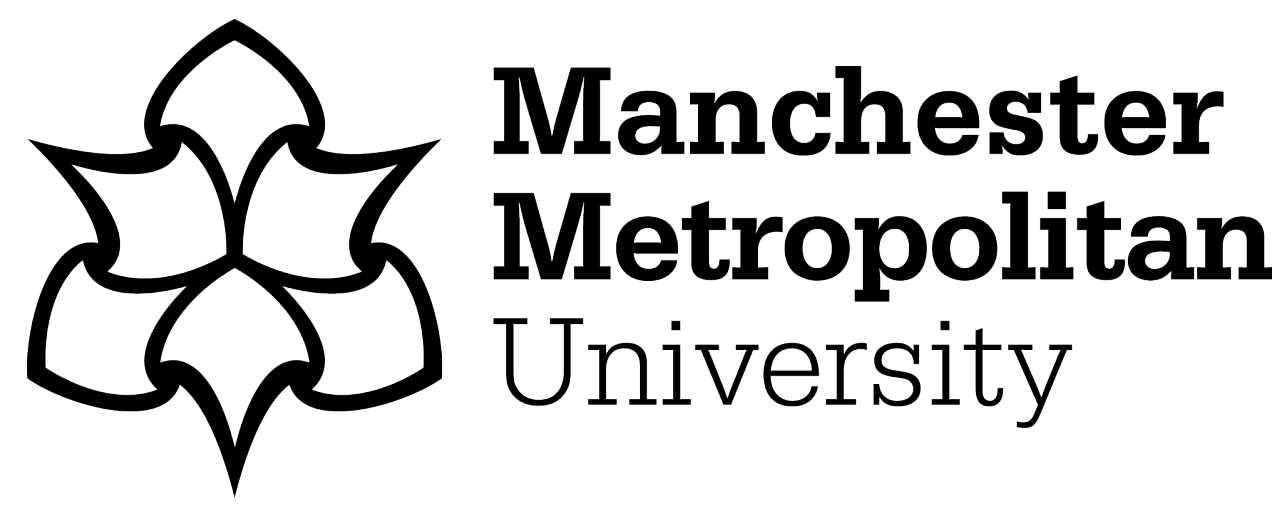

Ensslin, Astrid, Skains, Lyle, Riley, Sarah, Haran, Joan, Mackiewicz, Alison and Halliwell, Emma (2016) Exploring digital fiction as a tool for teenage body image bibliotherapy*. Digital Creativity, 27 (3). pp. 177-195. ISSN 1462-6268

Downloaded from: https://e-space.mmu.ac.uk/625723/

Version: Accepted Version

Publisher: Informa UK Limited

DOI: https://doi.org/10.1080/14626268.2016.1210646

Please cite the published version 


\title{
Exploring digital fiction as a tool for teenage body image bibliotherapy
}

\author{
Astrid Ensslin (University of Alberta) \\ Lyle Skains (Bangor University) \\ Sarah Riley (Aberystwyth University) \\ Joan Haran (University of Oregon) \\ Alison Mackiewicz (Aberystwyth University) \\ Emma Halliwell (University of West of England)
}

\begin{abstract}
This article reflects on the findings of the interdisciplinary 'TransForm' project, which ran between 2012 and 2014 and aimed to explore how reading and writing digital fictions might support young women in developing frameworks for more positive thinking regarding their body image. The project comprised the following stages: (1) a review and compilation of digital fictions thematizing and/or problematizing female corporeality; (2) a series of cooperative inquiries with three groups of young women (aged 16-19 years) over a period of five weeks, examining participants' responses to a selection of the previously compiled digital fictions, as well as the challenges these young women face in relation to body image; and (3) an interventionist summer school in which participants aged 16-19 explored body image issues via writing digital fictions. This article reports on the main observations and findings of each stage, and draws conclusions for future research needs in this area.
\end{abstract}

Keywords: digital fiction; body image; expressive writing; bibliotherapy; cooperative inquiry

\section{Introduction}

This article reports the findings of the 'TransForm' research programme (2012-2014), which fused social science, literary and media analysis to explore the possibilities of digital fictions as therapy through reading and/or writing, using body image concerns as an 
exemplar focus. Bibliotherapy is the use of directed fictional and nonfictional reading to help with psychological issues. It is 'an emerging clinical technique that has been found useful for treating various clinical problems' (Pardeck 2014, xi) related to 'emotional problems and mental illness' in 'people of all ages' (Barker 1995, 35). Writing therapy, or 'expressive writing,' is a form of 'expressive (emotional) disclosure' or 'written disclosure therapy' (Mugerwa and Holden 2012, n.p.). It tends to be used as an adjunct practice for example in cognitive behavioural therapy or cognitive analytic therapy 'to further more general treatment goals' (Bolton, Field, and Thompson 2006, 21), yet has found various less formalized, less clinical uses in more or less explicitly therapeutic writing groups.

To date bibliotherapy has relied mostly on storytelling structured by the paper medium in which novels developed, with their associated characteristics such as linear storylines and minimal reader control over how the story unfolds. Similarly writing therapy has primarily focused upon writing these same linear, traditionally structured print narratives for the benefit of mental and physical health. In contrast, digital fictions (DFs) can be nonlinear, with increased interactivity and reader agency. DFs are created in a digital medium and form a fusion of story and game that pursues its 'verbal, discursive and/or conceptual complexity through the digital medium' (Bell et al. 2010, n.p.); this medium is essential to the aesthetic and semiotic functions of DF. Most DFs are media-specific literary experiments, but some encourage the player/reader to think critically about issues such as new feminist subjectivities (Laccetti 2006), female corporeality and body image. The 'TransForm' project, funded by a Welsh Crucible grant that sought to produce innovative transdisciplinary research, comprised researchers from psychology, literary and digital media, and creative writing in order to explore the use of DF as a body image intervention in the forms of bibliotherapy and expressive writing.

Research shows body dissatisfaction in a significant proportion of the population, particularly for girls and women but also in boys and men; it is associated with negative affect, reduced levels of physical activity, onset of eating disorders, low aspirations and a range of risky behaviours, including steroid use in men and smoking in women (Grogan 2008). Body confidence interventions are therefore urgently needed for non-clinical populations, but few have demonstrable impact (Yagera et al. 2013). Characteristics of the more successful body image interventions implemented in schools include using collective interactive processes to develop critical thinking that challenges the thin ideal and common beliefs about appearance, health, and happiness (Halliwell and Diedrichs 2014). 
The 'TransForm' programme explored whether these interventions could be developed using creative practice through the medium of DF informed by bibliotherapy and expressive writing. In this article we outline some core findings of the TransForm project. We begin by offering a review of DF, existing insights into the effects of bibliotherapy and expressive writing, and previous research on body image. This is followed by a discussion of the programme's tripartite methodology, designed to address specific research questions: (1) a survey of feminist-corporeal DFs; (2) a series of cooperative inquiries with 13 female secondary school UK female students aged 16-19 in three cooperative inquiry groups, using DF as a medium-specific bibliotherapeutic tool; and (3) a summer school with 11 male and female students aged 16-19 piloting DF as a creative tool in combination with collective and interactive activities designed to facilitate reflexivity and critical thinking regarding body image.

\section{Theoretical background}

\subsection{Digital fiction and the decline of hypertext}

The term digital fiction generally refers to narrative forms of electronic literature and digital games that have a significant literary or verbal art component. Early forms include the Interactive Fictions (IFs) of the 1980s, such as Infocom's Zork (1980). Literary hypertext, or hypertext fictions, arrived in the late 1980s in the form of multilinear, networked narratives asking readers to interact with the text by clicking on hyperlinks. Depending on a reader's chosen pathways through the hypertext, different, contradictory and often logically incompatible stories might be constructed. Some readers of Michael Joyce's afternoon, a story (1987), for example, may arrive at a reading that involves a car accident killing the narrator's son; others may not encounter any information about an accident but rather read primarily about complex human relationships or indeed the narrator's psychopathological state of mind.

With the arrival of the World Wide Web and the explosion of multimedia editing software from the 1990s onwards came a diversification of literary-creative engagement with digital media. In response to hypertext fiction's failure to attract popular or indeed academic audiences beyond scholars interested in postmodernism and deconstruction at the time, digital writers started experimenting with more linear forms of DF, and multiple communication modes (image, sound, text). Kate Pullinger, Andy Campbell and Chris 
Joseph's episodic new media novel, Inanimate Alice (2005-2014), for example, is a conceptually sequential narrative that foregrounds the multisensory meanings and psychological effects that different modes of digital representation may have in various combinations, and it weaves in ludic (playful and game-like) elements such as point-andclick and first-person racing games.

The years following the hypertext era saw a general move away from the perceived alienating effects of hypertext as a basis for storytelling (e.g. Schneider 2005). This was supported by a number of empirical reader response studies documenting why readers of hypertext fiction often feel frustrated by the technology and narrative non-closure and therefore unable to enjoy the multiple options and endings offered to them (Pope 2006, Miall and Dobson 2001). With some experimental exceptions, such as Mark Marino's a show of hands (2006), hypertext was not revived as an artistically poignant means of digital literary expression until very recently; especially in its extreme, reader-unfriendly forms such as Eastgate's Storyspace, it has remained a niche phenomenon. Hypertextual elements are regularly interwoven in DFs (e.g. episode 4 of Inanimate Alice) to introduce elements of choice; yet DF researchers tend to agree that the 'age of hypertext' in its original poststructuralist embedding is past and we're now dealing with a far broader range of technological and creative options, a lot of which tend - anti-hypertextually, as it were towards linearity and closure.

Interestingly, a recent trend in creative gaming communities has been the use of the highly user-friendly, non-commercial online tool Twine to create what are essentially hypertext stories. Of particular relevance for this project is that Twine has become prominent within feminist and queer indie gaming circles, with Zoe Quinn's (2013) Depression Quest forming a centerpiece of the GamerGate harassment movement, and Choice: Texas (Kocurek and Whipple 2016) exploring reproductive healthcare access in Texas.

Notably, Twine stories are framed as 'games' to be 'played online' and added to 'playlists'. Hence, conceptually there has been a move away from literary to ludic appropriations of multilinear storytelling, and to an emphasis on the kind of (w)readerly empowerment that was falsely attributed to first generation hypertext fiction (see Ensslin 2007). Furthermore, this trend can be seen as a continuation of various educational projects that, since the advent of Storyspace, explored the pedagogic potential offered by hypertext as a productive and creative tool to students of writing, literature and modern languages (e.g. 
Joyce 1988 and Ensslin 2007). These projects confirmed that hypertext writing could facilitate access to and production of knowledge, help create new and creative linkages between seemingly disconnected ideas, promote organized and integrative thought, encourage collaborative, networked learning, and facilitate writing-in-chunks as minimalist composition practice (in line with new forms of writing in social media; cf. Ensslin 2007, 132). This article will demonstrate how hypertext's effective applications might be expanded to psychological and therapeutic uses, given the accessibility and participatory nature of Twine technology.

\subsection{Bibliotherapy and expressive writing}

Bibliotherapy, or therapeutic intervention through reading, has been used to improve body image and wellbeing (Doll and Doll 1997; Recob 2008). Similarly, therapeutic intervention through directed, intensely focused writing about a traumatic event, or expressive writing $(E W)$ is an established technique with long-term physical and mental benefits (Pennebaker 1997, 2000; Pennebaker and Chung 2011; Pennebaker and Seagal 2011). These benefits cross boundaries of race, age, gender, education, socioeconomics, and language. While the mechanism by which EW works to effect these changes remains open to speculation, it is largely agreed that the method's engagement in cognitive processing of traumatic experiences is what gives it a beneficial edge over other arts therapies or non-expressive writing alone (Pennebaker and Seagal 1999; Pennebaker 2004; Lange 1996; Lange, van de Ven, and Schrieken 2003).

Most of the research on expressive writing has focused on quantifiable measures of physical well-being, such as doctor's visits, trends in school grades, and changes in employment status, as well as specific applications in clinical populations such as cancer patients and people with mood disorders (Baikie, Geerligs, and Wilhelm 2012; Morgan et al. 2008). Few studies have been conducted that examine EW's efficacy in relation to body dissatisfaction. Those studies indicate that EW helps to reduce stress levels in young college women, which results in a lowered likelihood of eating disturbances (Arigo and Smyth 2012), and self-reported improvements in mood and quality of life in young women with negative body image (Earnhardt 2002). More generally EW was linked to increases in wellbeing for those with non-clinical depression and in implicit self-esteem of college-age females (Gortner, Rude, and Pennebaker 2006; O'Connor et al. 2011). 
More recent innovations in the use of EW have been conducted with digital technology and narrative form. Several studies have moved online entirely (e.g., Baikie, Geerligs, and Wilhelm 2012) finding for example that instant messaging's combined intimacy and physical distance allows deeper levels of emotional sharing, whether with real-life friends or online strangers (Dolev-Cohen and Barak 2013). Narrative writing has been found to help participants to cognitively process their negative experiences, whether that writing be expressive or narrative or both, thereby conferring benefits; the stories conveyed can have solid structures or not (Danoff-Burg et al. 2010), they can be either 'good' or 'bad' (Graybeal, Sexton, and Pennebaker 2002), the events described can be real or imagined (Pennebaker and Seagal 1999), and they can be told from a range of narrative perspectives (Pennebaker and Seagal 1999; Seih, Chung, and Pennebaker 2011). It appears that it is the cognitive processing of the negative emotions or traumatic events involved in constructing a narrative (structured or unstructured) that conveys health benefits, rather than any one particular approach.

\subsection{Body dissatisfaction}

Body dissatisfaction is prevalent and associated with distress, with for example $50 \%-70 \%$ of adolescent girls reporting body dissatisfaction (Wertheim and Paxton 2011). Body dissatisfaction is linked to having a higher weight-to-height ratio or body size misperception; to an internalization of the thin ideal (women), a drive for leanness or muscularity (men), engaging in social comparisons, strong gender identification, exposure to media, and the interactional effects between media exposure and psychological variables such as materialism and internalization of the thin ideal (Ashikali and Dittmar 2012; Grogan 2008; 2010). Outcomes of body dissatisfaction are associated with a range of psychological outcomes (e.g., low self-esteem and negative affect, such as shame), or risky behaviours such as restrictive eating or steroid use (Grogan 2008).

Traditionally psychologists employed an individualistic approach to this issue, conceptualizing body size perception as an emotional interference in an otherwise accurate cognitive-perceptual process (Blood 2005). Alternatively, a socio-cultural perspective highlights how body image is produced through interpersonal dynamics and cultural norms, for example, how social interactions teach people to objectify their bodies 
(e.g. Fredrickson and Roberts 1997) or how psychological traits such as valuing materialism interact with factors such as exposure to media representations that associate thin bodies with affluence and value (Ashikali and Dittmar 2012).

A third approach is informed by social constructionism and poststructuralism, which share an understanding that knowledge is produced through its socio-historic context. Thus body dissatisfaction is neither a failure of individual cognitive processes nor a person's fixed measurable aspect produced through interaction between individual and society. Instead, body image is a dynamic process produced through social interaction that itself is made possible by the socio-historical conditions of the protagonists (e.g., Gleeson and Frith 2006). Such work has shown, for example, how wider discourses of citizenship and health create a context where body size and shape become a proxy for both health and a person's moral worth (Riley et al. 2008).

Although higher self-esteem, less internalization of thin/muscular ideals, and fewer social comparisons predict positive body image in men and women (Grogan 2010), researchers have had little success translating this knowledge into effective interventions. Of the few successful body image interventions for school-aged girls, most have small effect sizes, and only a few show (limited) impact at three months post-intervention (Yagera et al. 2013). Those more successful interventions employ collective, interactive activities to develop critical thinking in relation to body image (Bird et al. 2013; Halliwell and Diedrichs 2014; Richardson and Paxton 2010; Yagera et al. 2013). The TransForm project sought to build on this work by adding another, hitherto ignored factor: the power of reading and constructing interactive stories to facilitate resilience.

\section{Methodology and findings}

The TransForm programme consisted of three consecutive studies, each building upon the previous stage. Study 1 was a content analytical survey of existing DFs broadly dealing with body issues. Study 2 was a qualitative thick data analysis of young women's responses to five exemplar DFs with body image as a theme. The participants explored their body image challenges, whether these were reflected in the stage one DFs, and the 
extent to which they could be reframed to produce multiple narrative storylines for potential DFs. Study 3 explored whether the techniques for developing storylines could be linked with digital, non-linear creative writing so participants could produce their own DFs with potential therapeutic effect.

\subsection{Study 1: Survey of feminist-corporeal digital fictions}

This study aimed to identify what digital fictions already exist that have a body image theme, what their aesthetic characteristics are, and whether or not they are suitable for under-age audiences. To this effect, an online survey was conducted to identify and content-analyze existing DFs written in English dealing with body image issues/embodiment. On the resulting list, feminist methods of reading were employed to identify transformative frameworks for thinking about body image.

The texts identified as potentially relevant for this study included Tale of Tales' literary horror game The Path (2009; 'TP'); Inanimate Alice (2005-2014; 'IA'); Shelley Jackson's hypertext fictions My Body - A Wunderkammer (1997, 'MB') and Patchwork Girl (1995; 'PG'), and her hypermedia novel The Doll Games (2001; 'TDG'); Caitlin Fisher's Flash hypermedia novel, These Waves of Girls (2001; 'TWG'); Christine Wilks's historical Flash fiction, Underbelly (2010), her ludic hypermedia fiction, Fitting the Pattern (2008; 'FTP'), her dialogic hypermedia installation, Sitting Pretty (2004; 'SP'), and her Flash movie, IntraVenus (2005); Annie Abrahams's Flash fiction, Ne me touchez pas / Don't Touch Me (2003; 'NMTP'); and Zoe Beloff's Flash installation, The Influencing Machine of Miss Natalija $A$ (2001; 'TIM').

Only five were found to be potentially suitable for the target age of the participants: $I A, M B$, Underbelly, TDG and FTP. This was due to a range of potentially alienating, confounding, and/or terrifying features in the remaining works, such as unusual and potentially bewildering textuality and narrativity (TIM; PG; SP; IntraVenus), allusions to female homosexuality (TWG), or allusions to sexual violence and abuse (TP; NMTP). In hindsight, this text selection might have been reduced even further because the participants identified alienating elements even in the chosen texts (see Section 3.2). The following section outlines the text analytical findings, combining formal questions with analyses of key body image perspectives, reading position (how readers are 'coded' into the text), and aesthetic features (the clustering of semiotic resources). 
At the time of this research, IA comprised four episodes following Alice through her development from a technology-savvy child to an experienced videogame programmer. Accordingly, the narrative voice evolves from child to mature adult, and so do Alice's interactions with her changing social and geographic environments. Alice is 'in-animate' in the sense that at no point in the story is her body shown to the reader - much in line with DF conventions (favoring settings and objects rather than characters). Nor does she explicitly talk about her body image. The text thus semiotically erases her corporeality for the sake of cyberfeminist ideals of writing and programming in specifically female ways. Alice presents a working alternative to the body-centrism facing contemporary young females; the fact that we're never told what she looks like communicates to the reader a paradigm shift representing (ideal) girlhood or femininity in popular culture. It is mainly for this reason that the text was selected.

Dating to the late 1990 s, $M B$ is a graphically enhanced hypertext, centred around the image of a coarsely sketched female body. The fiction is text heavy, with no animations or film; the only interactive elements are textual hyperlinks. The decision to include this text wasn't without reservations about the narrative discourse's potentially alienating effects on a teenage audience. However, since it poses a radical alternative to conventional media representations of ideal girlhood and femininity, we were interested in whether participants would, as a response, aestheticize their own perceived corporeal shortcomings in a more amenable fashion.

Underbelly is a historical Flash fiction about 19th century women working in Yorkshire mines. In this highly multimodal, fluid and interactive piece readers listen to 'voices of the past' - first-person audio of mining women narrating their physical ordeals. The women's historical voices mix with that of a contemporary female sculptor, chiseling female bodies for an artistic site converted from a Yorkshire mine. The reader's mouse movement triggers animations, and the narrative concludes with a visual representation of the wheel of fortune. This presents the reader with the three choices for the female artist: get pregnant; leave it to chance; or remain childless. Spinning the wheel generates a random outcome for each reader, who is thus led to compare her real life choices with those of the historical females represented.

Underbelly was found to be one of the most suitable texts for the intervention, due to its real-life, historical components and strong focus on female corporeality in times past, and 
in social groups where women were excluded from media consumption. We expected young women to find it engaging to compare their own social and media realities with those of the women in the DF, and to gain a more appreciative body image based on the insight that their life choices are infinitely more diverse today than those of young women who lived only 200 years ago.

$T D G$, like MB, bears Jackson's rebellious auteur stamp. Multimodally enriched by photographic images of mutilated dolls, TDG is autobiographical, reflecting on the author's childhood, particularly her and her sister's (rather crude) interactions with their dolls. Jackson's agenda is again to subvert popular media expectations of perfect (or impossibly perfected) commodified female bodies, epitomized by Mattel's Barbie dolls. The hypertext's sections resemble a media archive, comprising tapes, interviews, and artefacts documenting aspects of the doll games. The text was chosen with similar reservations as Jackson's $M B$, as images of mutilated dolls, combined with catalogue-like detail about playing with dolls' bodies - often sexually - was expected to create feelings of alienation or even disgust. The question was whether the participants would understand the dark humour underlying the narrative, and how they would apply that understanding to their own situation.

Wilks's FTP is an autobiographical memoir about her relationship with her perfectionist mother, who insisted the first-person teenage narrator wear the styles and sizes she deemed appropriate. Rather than making clothes to fit, she would make her daughters wear clothes that were too small for them, thus instilling the ambition to 'fit the pattern'. The text is 'played' using tailor's tools (pins, scissors, needles), interactive metaphors for cutting the text's shapes to open new text. The reader performs the narrator's memories while metaphorically cutting and patterns and fabric. Again, no character images are shown, yet the body image issues are pervasive and we expected young women to easily relate to FTP.

\subsection{Study 2: Cooperative inquiry}

This study aimed to address the following research questions:

- How do young women respond to the DFs identified in Study 1 ? 
- To what extent do these DFs reflect the stories that young women tell of their own body image challenges?

- What techniques can be identified for developing DFs that enable young people to retell their body image stories in positive ways?

Cooperative inquiry $(\mathrm{Cl})$ is an action research method useful for researching complex identity processes; participants act as co-researchers, reflecting on their experiences on a particular life issue in a series of small-group discussions and engaging in activities to develop that reflection in cycles of action-reflection (Riley and Reason 2015). This project used Cl to explore: young women's reactions to the available body image themed DFs; their body image challenges, and whether these mapped onto those of the existing DFs; whether the participants could be facilitated to reframe their body image challenges into narratives with multiple endings; and whether these narratives could be used to develop a future DF targeted at young women.

The Aberystwyth University Ethics Committee approved the study. A School and Further Education College granted permission to recruit participants. Fourteen female secondary school students, aged 16-19, majority white British, with a range of academic achievement and socioeconomic status, participated; the study excluded those with diagnosed eating disorders. Participant emails (spontaneous and requested) regarding their experiences of the project were kept for analysis.

Participants were divided into three friendship groups, meeting 4-5 times on a weekly basis, creating 17 hours of data. Each meeting was led by one of the research team, audio recorded for the purposes of thematic analysis, and structured as follows: participants commented on one of the selected DFs they had read/played prior to the meeting, reflecting on what they liked, disliked and how the reading-reflecting process might help them develop their thinking about body image. Participants would then engage in activities facilitating critical reflection within social interaction, first by identifying their body image challenges (e.g., when and where they felt self-conscious of their bodies) and then exploring ways to reframe these stories in more positive ways. Central to this process was Rudolph, Taylor, and Foldy's Learning Pathways Grid (LPG) (2001), a solution-focused facilitated activity for developing new frameworks for thinking about interpersonal challenges; LPGs were photographed for analysis. Finally, participants completed a questionnaire on their media use to contextualize the findings (Figure 1). The 
questionnaire revealed that participants used computers mostly for homework, followed by watching films and online TV. Most did not play games or listen to podcasts/radio on computers.

[FIGURE 1 HERE]

As expected, many elements in the selected DFs did not appeal to the young women. The most salient negative comments revolved around text-heaviness, which often caused the participants to lose interest halfway through the narrative. This reaction was particularly prominent in relation to the hypertexts (TDG, MB). Furthermore, in most cases participants found it difficult to relate to the female protagonists, either because their lives were seen to be too remote from their own (FTP); because of the multilinearity and perceived lack of closure of the text, confirming findings of previous empirical hypertext reading studies (e.g. Gardner 2003, Pope 2006, Miall and Dobson 2001); or because of the bizarre, depressing and often obscene ways in which typical childhood or female body themes are dealt with (TDG). The level of gory detail at which large stretches of $M B$ are narrated was also perceived as intrusive, making participants feel uncomfortable. Similarly, the beauty ideals communicated by $M B$ in particular evoked reactions of shock and disgust (e.g., hairy armpits being cool).

Participants felt instructions and introductions were often too brief and elusive (Underbelly, $M B, I A)$, which made it hard for them to relate to the female protagonists. Alice in particular was perceived to be aloof and distanced, acting as a detached observer rather than engaging with her observations more vividly. Participants also responded negatively to unresolved issues and unclosed story arcs (FTP), to multiple synchronous layers of sound (overlapping voices in Underbelly), to experimental and unfamiliar ('creepy') sound effects (Underbelly, $I A)$, as well as to what was generally perceived as weird behaviour $(M B$, $T D G)$.

Participants commented positively on high levels of realism and story-drivenness (such as in the later episodes of $I A$ ); on concise and linear story development (Underbelly); and on the fact that DF protagonists tend to be invisible and therefore interesting to explore imaginatively; they appreciated the way music is used in $I A$ to build suspense, and the use 
of exotic locations. Perceived positive aspects of $M B$ included the observation that reading about the narrator's body made participants reflect on their own relationship with their bodies, and feel more confident about their bodies' unique features - which confirmed some of our hypothetical speculations. Some of them also liked the high level of corporeal and psychological detail conveyed by MB's narrator. In Underbelly, participants enjoyed having choices in the final 'wheel of fortune' section because it made them reflect on the different choices they had in life as opposed to historical women - again confirming our expectations; they also liked the displayed timer in Underbelly because it indicated where in the reading process they were at any given moment. In FTP they enjoyed the high levels of interactivity, and could relate to the theme of growing up and having to find one's own identity vis-a-vis parental and societal expectations, especially in relation to the female body.

For the development of future DFs tailored to young women's needs, participants brainstormed a list of undesirable and desirable design elements (Table 1). On the negative list are text-heaviness, inappropriate levels of instruction, unrelated topics, negativity, lack of closure, and weirdness. Instead, they desired strong levels of interaction and backstory; contextualized instructions on how to read and interact with the text; indicators of narrative location (e.g., timers and maps); relatable issues and characters similar to their own lives and relationships; and division between the mundane (e.g. school) and the exotic (foreign countries or fantasy worlds), allowing readers to juggle and negotiate those different spheres. Finally, they requested the inclusion of navigational choices leading to different outcomes, positive and negative.

An interesting observation to be made is that there were not any specifically negative comments about hypertext as a technology or tool for creative writing. What was pointed out as unpleasant, rather, was the frequent use of hypertext to create stories without closure or endings. Indeed, the final observation reflected in the previous paragraph suggests that hypertextual choices and clearly defined, different endings, might work well with young females - as readers and writers.

\section{[TABLE 1 HERE]}




\subsection{Study 3: digital writing workshop}

This study aimed to address the following research questions:

- To what extent can young people retell their stories through the medium of DF, creating the potential for a bank of sharable, playable stories of common body image challenges and their potential solutions?

- To what extent does making these DFs create resilience in relation to body image?

This study incorporated an interventionist DF workshop that implemented a mixed-method design of $\mathrm{Cl}$ with media-specific expressive writing, in which participants were facilitated to produce a DF based on a personal body image challenge. The workshop was conducted as an Aberystwyth University summer school module, four hours/day, Monday-Thursday, for two weeks. Participants were young people identified as having university potential, but in need of support (e.g., low socioeconomic status, mental health vulnerabilities, etc.); they were recruited at a summer school open day.

During the recruitment the purpose of the module as research was clearly stated. Participants were excluded if they were diagnosed with an eating disorder, and were reminded that they could withdraw their data from the research project while still remaining in the module, or could move to another module. Of the twelve students registered, three withdrew due to dissatisfaction with the module's emphasis on creative writing rather than theoretical psychology; nine completed the module (four males, five females, aged 16-19).

Participants completed a journal reflecting on the workshop content, and a DF on the subject of body image. The workshop combined digital writing, DF readings (a modified list from Study 1, to incorporate findings from Study 2, and to relate to boys as well as girls), and critical reflection activities (developed in Studies $1 \& 2$ ). Appendix $A$ is an outline of the full two-week module, including the topics and goals of each session, activities, and homework.

Participants also completed two questionnaires: 1) the media-use questionnaire used in Study 2, and 2) a body image questionnaire that evaluated body dissatisfaction and positive body image (Brown, Cash, and Mikulka 1990, Tylka and Wood-Barcalow 2015). 
Participants completed the body image questionnaire online, out of class, before and after the summer school.

The media questionnaire was analyzed using descriptive statistics, the body image questionnaire by descriptive and inferential statistics. Other data included audio recordings of the sessions, images of the LPGs and other session outcomes, participant journal entries, participant DFs, participant module evaluation forms, and written observations of the researchers. Of particular interest were the participant observations during readings and activities, their journal entries on the readings and the digital writing process, and the final DFs.

In terms of findings, the students did not engage well with the DFs used to introduce them to the genre. Of the suggested readings (Because You Asked by Alan Bigelow [2007], Opacity by Serge Bouchardon et al. [2012], Underbelly, MB, FTP and The Mating Ritual of The Modern Man by Susan Gibb [2009; 'TMRMM']), they only seemed to respond to the latter two. The participant response to these texts echoes those from the Cooperative Inquiry study (Section 3.2) in that they desired better guidance on how to read the more technologically complex texts (Opacity, Underbelly, MB), while they found more narrativedriven texts with linear elements easier to engage with (FTP, TMRMM).In particular, they conducted multiple readings of the hypertext fiction TMRMM, both within and between different in-class reading groups. They engaged with the game-like aspects of the hypertext, trying to find the 'winning' reading that would result in a positive outcome for the player-character in his attempts to find the 'right' mate.

Throughout the workshop, girls typically produced more outputs during $\mathrm{Cl}$ activities. One group, composed entirely of girls, even became self-conscious about the higher volume of their output when compared to the other groups. The boys began the workshop with the attitude that they did not have body awareness or self-consciousness issues. As the activities progressed, however, they gained an awareness of some issues, as one participant relayed his reluctance to take his shirt off at the beach, comparing his body to that of a 'thinner' friend. In the second week, he reported going to the beach over the weekend with friends, and taking his shirt off for the first time, an anecdotal but positive outcome of the Week 1 thematic analysis segment of the workshop. 
We anticipated the Life History Chart (LHC) (Days 3-4) and the LPG (Days 5-6) activities would directly feed into the participant DFs; in practice, however, the participants at this stage were so engrossed in creating their DFs that they engaged less actively with the activities in Week 2. The participants noted that their DFs were already significantly progressed, and thus they could not incorporate connections made in the LPG by this point. They were also increasingly focused on their DFs, both as a fun and engaging activity, and as the primary assessment for the workshop module.

Eight out of nine participants noted engagement with the chosen digital, hypertextual writing tool, Twine (http://twinery.org), or writing their DF as the most useful/enjoyable element of the course on their evaluations. During several sessions the students requested to work on their DFs as opposed to other activities, and Week 2 found most of them arriving early and/or staying late working on them. Participants mastered Twine much more quickly than anticipated, which turned their attention away somewhat from activities such as the LHC and LPG; we had anticipated the participants progressing more slowly on the DFs, needing narrative input from these activities in order to complete them. For future interventions we suggest the psychological engagement activities be moved earlier in the schedule, in order to focus their attention on psychological activities early on and accommodate for the short learning curve related to the technology.

All of the submitted DFs incorporated hyperlinks chosen by the reader, resulting in nonlinear, branching, rhizomatic, and/or hybrid architectures. All DFs save one explored topics intimately related to body image and/or self-consciousness; some were completely fictional, some were loosely autobiographical, and some were memoirs, incorporating significant memories and even personal images.

Four students ( 3 female, 1 male) completed the body image questionnaire both before and after attending the summer school (highlighting the disadvantage of not including the questionnaire as an in-class activity). These numbers are small and the analysis should be treated with caution, as with small sample sizes it is more difficult to identify small or medium effect size changes in outcomes. Amongst these students there was a significant increase in level of body appreciation (a measure of positive body image) ( $\mathrm{M}_{\text {pre }}=3.6$, $\left.\mathrm{SD}_{\text {pre }}=.89, \mathrm{M}_{\text {post }}=4.00, \mathrm{SD}_{\text {post }}=.73, \mathrm{t}(3)=-2.31, \mathrm{p}=.05\right)$. Although body satisfaction (how participants rated their satisfaction with areas of their body) also increased, this change was not significant $\left(M_{\text {pre }}=3.06, S_{\text {pre }}=1.32, M_{\text {post }}=3.56, S_{\text {post }}=1.01, t(3)=-\right.$ 
2.31, $p=.10)$. All four students agreed $(n=3)$ or strongly agreed $(n=1)$ that the session had a positive influence on their body image. Their qualitative feedback included thinking differently about the way bodies are presented in the media, understanding that other people too are self-conscious and respecting their bodies. This feedback also reiterated enjoyment in making the digital fictions.

\section{Discussion}

The TransForm project sought to identify extant DFs applicable for bibliotherapy for young women with body image issues, and to explore whether reading and writing DFs had a positive effect on young people's body image. Few extant DFs, however, were found to be suitable for bibliotherapy purposes in this area. Those that are applicable have unconventional structures and/or inappropriate content for the target age group. This is not surprising, as these pieces are largely constructed as artistic exploration of self and form, rather than as teaching or therapy tools (with the possible exception of $I A$, which is not specifically on-topic, but is constructed for the purposes of education, that of facilitating primary schoolchildren's engagement with digital tools). With the exception of the growing number of Twine texts, many of which have emerged after this research was conducted, extant DFs are experimental art, generally not aimed at an unfamiliar, mainstream audience, and certainly not for the purposes of addressing body image issues.

In general, the conventions of DF are unfamiliar to the target subjects. The technology is familiar (hyperlinks, animation, image, text, etc.), but the narrative structures are not. These unfamiliar structures - which are conventional with DFs - and the often obfuscated, subtle, or absent narrative structures largely confused participants, who could not parse them well enough to engage with the protagonists or the text's purpose. Even when subjects are familiar with the conventions, the 'weirdness' of the content can render a text inappropriate for bibliotherapy purposes, and can open the possibility of triggering other issues. While the familiarity issue can be overcome with time and continued exposure to DFs, the inability of the participants to engage fully with the protagonists and narratives is more problematic when the text is being used as bibliotherapy. If the participant cannot identify the text's purpose or meaning because of unfamiliar textual architecture, nonlinear 
structures, and/or lack of closure, then it is highly likely the text's efficacy as bibliotherapy will be limited.

After a survey of DFs and gathering responses from the focus group in Study 2, only one DF, FTP, seemed adequately suited for this task; indeed, FTP was the text the participants in Study 2 most related to. It has a recognizable and relatable protagonist, who remains unseen, permitting the reader to put herself in the story. The straightforward navigation, with progress markers and point-and-click interactions, allowed the participants to absorb the content of the memoir and reflect upon it, rather than wallow in confusion over how to read or play the narrative. The piece, however, still permits interaction, and user-directed navigation, which the participants found engaging as long as it does not begin to obfuscate the narrative. When asked to identify desirable aspects of DFs, the qualities listed matched FTP quite well; it is therefore likelythat this DF will continue to be used in this research as a bibliotherapy tool.

On the other side of the equation, we found that participants were highly engaged in creating digital fictions, particularly through Twine. They embraced the notion of multiple pathways through the narrative, but eschewed the lack of closure so common to extant DFs; all of the participants designed their DFs with clear, conclusive endings (one or more). This tendency points to a desire to explore different life choices available to them, whether small scale or large, and expressive writing through hypertext affords them the opportunity to pursue these choices - as many as they like - to their narrative conclusions. The activity of designing, writing, testing, and reading these texts encourages cognitive processing of negative events which is theorized to be the therapeutic mechanism of expressive writing.

Unlike writing print fiction, however, digital fiction writing requires a specific skillset that is not typically taught to students in primary or secondary education (at least it is not part of required curriculum in the same way writing is). In order for subjects to engage in creating DFs as expressive writing, a tutor with a specific skillset is required to teach participants about reading and writing hypertexts, to troubleshoot technological issues, and to offer knowledgeable feedback on the participants' work. While most participants quickly grasped the basics of Twine, their enthusiasm pushed them to request more advanced options (such as changing the site's appearance, adding images and sound, etc.) beyond what was originally planned for the intervention. As no existing tutorials were available for 
these functions, one of the researchers created a new one specifically for these purposes. This sort of expertise cannot be expected of every group running a DF-intervention for body image issues, and must therefore be addressed with a more robust system of texts and tutorials.

Thus certain conventions of DF give it a high potential as bibliotherapy: branching structures offering crucial choices based on the topic of body image; non-visible protagonists and conventional use of the second person perspective permitting the reader/player to personify the role and its relevant choices; multiple communication modes combining text, image, and sound; and interactivity that further engages the reader/player in the narrative choices. These same conventions make digital writing highly suitable for expressive writing on body image issues, as the structures offer the writer opportunity to imagine multiple actions and outcomes, and to personalize the narrative with autobiographical notes, including customization, images, and music. While the extant DFs do not offer many options for bibliotherapy intervention for body image issues in young women, the potential exists for them to be created, and to be highly suitable and effective once they are.

\section{Conclusion}

The TransForm project has completed the initial phase of research, exploring whether DFs are worth pursuing as bibliotherapy and expressive writing tools for young people with body image issues. While the research is still preliminary, it shows significant promise for offering subjects an engaging, interactive exploration of negative events related to body image, encouraging cognitive processing of these events. While few DFs currently exist that are suitable for bibliotherapy on body image issues, we were able to identify criteria that subjects respond positively toward, which can be applied to future surveys and possibly purpose-built DFs for bibliotherapy. Further, participants were extremely responsive to digital writing as expressive writing; their DFs all demonstrated these identified criteria, and the engagement with the process was enthusiastic.

Another finding, gained mostly through the successful use of Twine, is that hypertext remains a powerful 'constructive' environment (Joyce 1988; Ensslin 2007) in need of repurposing. One such promising new direction is to use the structures, choices, and 
interactivity for bibliotherapy and expressive writing. The conventions of DFs give subjects relatable protagonists, the ability to explore various life choices to their conclusions, and to reflect upon the consequences of different options. The potential for cognitive processing of negative events is significantly heightened, particularly when DFs are used for expressive writing; participants must imagine, process, write, and conclude multiple options, exploring them fully. Thus, in the heyday of participatory media, hypertext'sinherent ability to permit the digital writer to examine self and society has come full circle. Put to use in a therapeutic intervention, this can result in positive effects for the participants' body image.

Further research is still needed, as is further creative experimentation with alternative technologies such as the multilinear, multimodal online publishing platform Scalar. We have identified an urgent need for purpose-built DFs for bibliotherapeutic intervention for young people for common body image issues. Additional focus groups in the target population will then be conducted, to examine more deeply DF's effects on body image. We also suggest significant adjustments to the arrangement of the digital writing module in Study 3, emphasizing the psychological interventions early on, as well as additional DF readings (ideally with purpose-built DFs and samples from previous participants), with the digital writing component moved back, allowing for full engagement with the LHC and LPG activities prior to starting their expressive writing. Both studies - bibliotherapy focus group and expressive writing group - need to be conducted with more participants and with a longer follow-up period (3-6 months) to examine long-term effects.

The applications of digital fiction (and in particular compositional uses of hypertext) for therapeutic intervention in young people with body image issues are promising, particularly in its use as expressive writing. While more research is recommended, these preliminary studies indicate that young people respond positively to certain types of digital fiction, especially if and when they are perceived as game-like, and that the positive effects of reading and writing these works could be significant.

\section{Research affiliations:}

The research for this article was conducted at Bangor University and Cardiff University (Study 1), and Aberystwyth University (Studies 2 and 3).

\section{Acknowledgements:}


This work was supported by the Welsh Crucible; further thanks goes to Sonia Fizek, Yi

Gong and the IT and summer school teams at Aberystwyth University.

\section{Disclosure statement:}

The authors have no financial interest or benefit arising from the direct applications of their research.

\section{References}

Abrahams, A. 2003. Ne me touchez pas / Don't Touch Me. Accessed June 62015. http://www.bram.org/toucher.

Arigo, D., and J.M. Smyth. 2012. The benefits of expressive writing on sleep difficulty and appearance concerns for college women. Psychology \& Health, 27: 210-26.

Ashikali, E.M., and H. Dittmar. 2011. The effect of priming materialism on women's responses to thin-ideal media. British Journal of Social Psychology, 51: 514-533.

Baikie, K.A., L. Geerligs, and K. Wilhelm. 2012. Expressive writing and positive writing for participants with mood disorders: An online randomized controlled trial. Journal of Affective Disorders 136: 310-319.

Barker, R. L. 1995. The social work dictionary. $2^{\text {nd }}$ ed. Silver Spring, MD: NASW.

Bell, A., A. Ensslin, D. Ciccoricco, H. Rustad, J. Laccetti, and J. Pressman. 2010. A [s]creed for digital fiction. electronic book review, 7 March 2010. Accessed June 6 2015. http://www.electronicbookreview.com/thread/electropoetics/DFINative.

Beloff, Z. 2001. The influencing machine of Miss Natalija A. Accessed June 72015. http://www.zoebeloff.com/influencing.

Bigelow, A. 2007. Because you asked. Accessed June 72015. http://www.webyarns.com/BecauseYouAsked.html.

Bolton, G., V. Field, and K. Thompson. 1995. Introduction. In Writing books: A resource handbook for therapeutic writing workshops and activities, ed. G. Bolton, V. Field and K. Thompson, 13-32. London: Jessica Kingsley Publishers. 
Bird, E.L., E. Halliwell, P.C. Diedrichs, and D. Harcourt. 2013. Happy being me in the UK: A controlled evaluation of a school-based body image intervention with pre-adolescent children. Body Image 10: 326-334.

Blood, S. 2005. Body work: The social construction of women's body image. London: Routledge.

Bouchardon, S., L. Dumas, V. Volckaert, and H. Zénouda. 2012. Opacité/Opacity. Accessed June 7 2015. http://i-trace.fr/opacity.

Brown, T.A., T.F. Cash, and P.J. Mikulka. 1990. Attitudinal body-image assessment: Factor analysis of the body-self relations questionnaire. Journal of Personality Assessment 55: 135-144.

Danoff-Burg, S., C.E. Mosher, A.H. Seawell, and J.D. Agee. 2010. Does narrative writing instruction enhance the benefits of expressive writing? Anxiety, Stress, and Coping 23: 341-352.

Dolev-Cohen, M., and A. Barak. 2013. Adolescents' use of instant messaging as a means of emotional relief. Computers in Human Behavior, 29: 58-63.

Doll, B., and C.A. Doll. 1997. Bibliotherapy with young people. Englewood, Colorado: Libraries Unlimited.

Earnhardt, J.L., D.M. Martz, M.E. Ballard, and L. Curtin. 2002. A writing intervention for negative body image. Journal of College Student Psychotherapy 17: 19-35.

Ensslin, A. 2007. Canonizing hypertext: Explorations and constructions. London: Continuum.

Fisher, C. 2001. These waves of girls. Accessed June 72015. http://www.yorku.ca/caitlin/waves.

Gardner, C. 2003. Meta-interpretation and hypertext fiction: A critical response. Computers and Humanities 37: 33-59.

Gibb, S. 2009. The mating ritual of the modern man. Accessed June 72015. http://www.susangibb.net/blog2/wpcontent/uploads/100stories/100thematingritual/titlec.html. 
Gleeson, K., and H. Frith. 2006. (De)constructing body image. Journal of Health Psychology 11: 79-99.

Gortner, E.-M., S.S. Rude, and J.W. Pennebaker. 2006. Benefits of expressive writing in lowering rumination and depressive symptoms. Behavior Therapy 37: 292-303.

Graybeal, A., J.D. Sexton, and J.W. Pennebaker. 2002. The role of story-making in disclosure writing: The psychometrics of narrative. Psychology \& Health 17: 571-581.

Grogan, S. 2008. Body image: Understanding body dissatisfaction in men, women and children. 2nd ed. London: Routledge.

Grogan, S. 2010. Promoting positive body image in males and females: Contemporary issues and future directions. Sex Roles 63: 757-765.

Halliwell, E., and P.C. Diedrichs. 2014. Testing a dissonance body image intervention among young girls. Health Psychology 33: 201-204.

Infocom. 1980. Zork. Cambridge, MA: Infocom.

Jackson, S. 1995. Patchwork girl, or, a modern monster. Cambridge, MA: Eastgate Systems.

Jackson, S. 1997. My body - a wunderkammer. Accessed June 72015. http://www.altx.com/thebody.

Jackson, S. 2001. The doll games. Accessed June 72015.

http://www.ineradicablestain.com/dollgames.

Joyce, M. 1987. afternoon, a story. Cambridge, MA: Eastgate Systems.

Joyce, M. 1988. Siren shapes: Exploratory and constructive hypertexts. Academic Computing 3 : 10-14; 37-42.

Kocurek, C. and A. Whipple. 2016. Choice: Texas. Accessed May 102016. http://playchoicetexas.com/index.php.

Laccetti, J.M. 2006. Towards a loosening of categories: Multi-mimesis, feminism, and hypertext. electronic book review, 17 March 2006. Accessed May 92016. http://www.electronicbookreview.com/thread/writingpostfeminism/appropriated. 
Lange, A. 1996. Using writing assignments with families managing legacies of extreme traumas. Journal of Family Therapy 18: 375-388.

Lange, A., J.-P. van de Ven, and B. Schrieken. 2003. Interapy: Treatment of posttraumatic stress via the internet. Cognitive Behaviour Therapy 32: 110-24.

Marino, M. 2006. a show of hands. Accessed June 3rd 2015.

http://hands.literatronica.net/src/initium.aspx.

Miall, D.S., and T. Dobson. 2001. Reading hypertext and the experience of literature. Journal of Digital Information 2. Accessed 18/02/15.

https://journals.tdl.org/jodi/index.php/jodi/article/view/35/37.

Morgan, N.P., K.D. Graves, E.A. Poggi, and B.D. Cheson. 2008. Implementing an expressive writing study in a cancer clinic. The Oncologist 13: 196-204.

Mugerwa, S., and J.D. Holden. 2012. Writing therapy: A new tool for general practice? British Journal of General Practice 605: 661-663.

O'Connor, D.B., R. Hurling, H. Hendrickx, G. Osborne, J. Hall, E. Walklet, A. Whaley, and H. Wood. 2011. Effects of written emotional disclosure on implicit self-esteem and body image. British Journal of Health Psychology 16: 488-501.

Pardeck, J.A. 2014. Using books in clinical social work practice: A guide to bibliotherapy. New York: Routledge.

Pennebaker, J.W. 1997. Writing about emotional experiences as a therapeutic process. Psychological Science 8: 162-166.

Pennebaker, J.W. 2000. Telling stories: The health benefits of narrative. Literature and Medicine 19: 3-18.

Pennebaker, J.W. 2004. Theories, therapies, and taxpayers: On the complexities of the expressive writing paradigm. Clinical Psychology: Science and Practice 11: 138-142.

Pennebaker, J.W. 2014. Some suggestions for running a confession study. Accessed Oct 32014.

http://homepage.psy.utexas.edu/HomePage/Faculty/Pennebaker/Reprints/Hints.pdf. 
Pennebaker, J.W., and C.K. Chung. 2011. Expressive writing: Connections to physical and mental health. In The Oxford handbook of health psychology, ed. H.S. Friedman, 417436. Oxford: Oxford University Press.

Pennebaker, J.W., and J.D. Seagal. 1999. Forming a story: The health benefit of narrative. Journal of Clinical Psychology 55: 1243-1254.

Pope, J. 2006. A future for hypertext fiction. Convergence: The International Journal of Research into New Media Technologies 12: 447-65.

Pullinger, K., A. Campbell, and C. Joseph. 2005-2016. Inanimate Alice. Accessed May 6 2016. http://www.inanimatealice.com.

Quinn, Z. 2013. Depression Quest. Accessed May 102016. http://www.depressionquest.com.

Richardson, S.M., and S.J. Paxton. 2010. An evaluation of a body image intervention based on risk factors for body dissatisfaction: A controlled study with adolescent girls. International Journal of Eating Disorders 43: 112-122.

Riley, S.C.E., M. Burns, H. Frith, and P. Markula, eds. 2008. Critical bodies:

Representations, practices and identities of weight and body management. London: Palgrave.

Riley, S., and P. Reason. 2015. Co-operative inquiry: An action research practice. In Qualitative psychology: A practical guide to methods, ed. J. Smith. London: Sage.

Rudolph, J.W., S.S. Taylor, and E.G. Foldy. 2001. Collaborative off-line reflection: a way to develop skill in action science and action inquiry. In Handbook of action research: Participative inquiry and practice, ed. P. Reason and H. Bradbury, 405-412. London: Sage.

Schneider, R. 2005. Hypertext narrative and the reader. European Journal of English Studies 9: 197-208.

Seih, Y.-T., C.K. Chung, and J.W. Pennebaker. 2011. Experimental manipulations of perspective taking and perspective switching in expressive writing. Cognition \& Emotion 25: 926-938. 
Stuckey, H.L., and J. Nobel. 2010. The connection between art, healing, and public health: A review of current literature. American Journal of Public Health 100: 254-63.

Tale of Tales. 2009. The Path. Accessed June 7 2015. http://tale-oftales.com/ThePath/downloads.html.

Taylor, S.S., J.W. Rudolph, and E.G. Foldy. 2008. Teaching reflective practice in the action science/action inquiry tradition: Key stages, concepts and practices. The SAGE Handbook of Action Research: Participative Inquiry and Practice, $2^{\text {nd }}$ ed, ed. P. Reason and H. Bradbury, 656-668. London: Sage.

Tylka, T.L., and N.L. Wood-Barcalow. 2015. The body appreciation scale-2: Item refinement and psychometric evaluation. Body Image 12: 53-67.

Wertheim, E., and S. Paxton. 2011. Body image development in adolescent girls. In Body image: A handbook of science, practices and prevention, ed. T. Cash and L. Smolak, 76-84. Yew York: Guilford Press.

Wilks, C. 2004. Sitting Pretty. Accessed June 72015. http://crissxross.net/MovingPix/BeforeWeBegin/index.html.

Wilks, C. 2005. IntraVenus. Accessed June 72015. http://crissxross.net/MovingPix/IntraVenus.html.

Wilks, C. 2008. Fitting the Pattern. Accessed June 72015. http://crissxross.net/elit/fitting_the_pattern.html

Wilks, C. 2010. Underbelly. Accessed June 72015. http://crissxross.net/elit/underbelly.html.

Yagera, Z., P.C. Diedrichs, L.A. Ricciardelli, and E. Halliwell. 2013. What works in secondary schools? A systematic review of classroom-based body image programs. Body Image 10: 271- 281. 
Appendix A (ANONYMIZED)

Study 3: Summer School Syllabus

Psychology and Digital Fiction

Summer 2014

\section{Instructors: \\ Email:}

\section{Course Description}

This module consists of interactive workshops led by staff from Psychology and Creative Media Industries. It is designed to be an opportunity for students to reflect and develop different ways of thinking about body image and to communicate these in the form of a digital fiction (online interactive story). The module is part of a pilot study to explore the use of digital fictions to enhance psychological well being. The project aims to facilitate reflection tools in the participants, widen their experience of psychological and creative media practices, and develop their knowledge of digital storytelling and digital fiction technology.

Participating should be fun and engaging but will also require a commitment to thinking about personal issues and respecting the experiences and feelings of other class members. On this course students will:

- Learn about digital storytelling: characterisation, narrative structure and digital construction

- Critically reflect as individuals and in groups on personal experience in relation to body image challenges

- Apply this learning to produce their own digital fiction addressing a body image issue

Comment to applicants: Please note male and female applicants are invited to apply, unless you have been diagnosed with an eating disorder, either now or when younger. In this circumstance participating in this project may be triggering and as your psychological health is paramount, you are therefore not invited to apply.

\section{Course Content}

- Understanding character and narration in digital storytelling

- Exploring personal experiences of body image challenges and their solutions

- Developing a digital story in which a character moves through a multiple choice narrative story line that addresses a body image challenge

- Learning open access software Twine (twinery.org)

\section{Learning Outcomes}

Through this module, students will:

1) Show via creative practice an awareness of issues related to body image

2) Demonstrate an awareness, through discussion and practice, of how to construct personal narratives

3) Engage in critical thinking regarding experiences of body image challenges

4) Demonstrate an ability to use the open access software Twine

5) Demonstrate an ability to use digital images in line with intellectual property (IP) rights. 


\section{Learning Journal (20\%)}

A daily journal responding to and reflecting upon topics, activities, and exercises covered in the module.

Learning Outcomes: 1, 2, 3, 4

Due Date: Beginning of Session 5.

\section{Creative Portfolio (80\%)}

A short piece of digital fiction (500 words with images, or 5 minutes in duration) articulating a personal narrative related to issues of body image.

Learning Outcomes: 1, 2, 4, 5

Due Date: Within 24 hours of Session 8.

\section{Assigned Readings:}

(PARTLY ANONYMIZED)

\section{Digital Fictions:}

- Because You Asked by Alan Bigelow - http://www.webyarns.com/BecauseYouAsked.html

- Underbelly by Christine Wilks - http://crissxross.net/elit/underbelly.html

- The Body by Susan Gibb - http://www.susangibb.net/blog2/wpcontent/uploads/100stories/38thebody/titlec.html

- Opacity by Serge Bouchardon - http://i-trace.fr/opacity/

- Fitting the Pattern by Christine Wilks - http://crissxross.net/elit/fitting_the_pattern.html

- The Mating Ritual of the Modern Man by Susan Gibb - http://www.susangibb.net/blog2/wpcontent/uploads/100stories/100thematingritual/titlec.html

\section{Media:}

- 'Fabulous Webchat with Body Gossip' YouTube video: https://www.youtube.com/watch? $\mathrm{v}=\mathrm{ohPqsawn6UY}$.

- Creative Commons Licensing: http://creativecommons.org/

- Cyberpsychology Exercises: http://anybody.squarespace.com/cyber_psychologist/2006/3/23/exercise-1-fat-fantasy.html

- 'Dove Evolution' YouTube video - https://www.youtube.com/watch?v=iYhCn0jf46U

\section{Recommended Reading:}

- Dove Real Beauty Sketches: https://www.youtube.com/results? search query=dove+real+beauty+sketches

- Body Gossip's YouTube channel: https://www.youtube.com/user/BodyGossip

- See the full list on this module's Blackboard site.

\section{Module Structure:}

The module meets four times a week (Mon-Thurs) for two weeks, in two-hour seminar sessions during the Pre-HE Summer Session.

Details for each session, including readings and exercises, will be available on this module's Blackboard site. 
Module Outline

\begin{tabular}{|c|c|c|}
\hline Session & $\begin{array}{c}\text { Activities } \\
\end{array}$ & Homework \\
\hline 1 & $\begin{array}{l}\text { Introductions: Students, Instructors, and Digital } \\
\text { Fictions } \\
\text { - Intro to the instructors } \\
\text { - Module overview } \\
\text { - 'Who are you?' game - intro to the students } \\
\text { - Exercise: Getting to Know Digital Fictions } \\
\text { - Exercise: Avatar Designs }\end{array}$ & $\begin{array}{l}\text { - Play at least one DF from the reading list on Blackboard. Start } \\
\text { your journal with a reflection (e.g., on the characteristics of DFs, } \\
\text { how they're different/unique, etc.). } \\
\text { - Fill out the body image questionnaire if you don't mind doing } \\
\text { so. }\end{array}$ \\
\hline 2 & $\begin{array}{l}\text { Body Image Challenges } \\
\text { - Homework reflection } \\
\text { - When \& where activity } \\
\text { - Representing themes of body image } \\
\text { challenges in multiple media } \\
\text { - Intellectual property overview } \\
\text { - Exercise: Building a Media Representation } \\
\text { of Challenges }\end{array}$ & $\begin{array}{l}\text { - Journal: } \\
\text { O TWO first person diary entries of a body image story on one } \\
\text { of the themes you've discussed today: } \\
\text { - One written from your perspective. } \\
\text { - One written from someone else's perspective. } \\
\text { - Have at least one to share in the next session. } \\
\text { OR } \\
\text { O Look up Critical Bodies, read a chapter and write a first } \\
\text { person story inspired by what you've read. } \\
\text { - Watch 'Fabulous Webchat with Body Gossip' YouTube video: } \\
\text { https://www.youtube.com/watch?v=ohPqsawn6UY. } \\
\text { - More time? Play some more DFs, thinking about how the body } \\
\text { is represented. }\end{array}$ \\
\hline 3 & $\begin{array}{l}\text { Life History Charts and Narrative } \\
\text { - Share \& discuss journal entries. } \\
\text { - Exercise: Interview each other \& create life } \\
\text { history charts. } \\
\text { - Introduction to Twine }\end{array}$ & $\begin{array}{l}\text { Using Twine (twinery.org), build a ' } 3 \text { moment' mini-story from } \\
\text { your life history chart (or diary entries or other memories). Don't } \\
\text { forget to journal about it. }\end{array}$ \\
\hline 4 & $\begin{array}{l}\text { Strategic Actions for Challenges } \\
\text { - Brainstorm strategies for body confidence. } \\
\text { - Exercise: Free writing for strategic actions } \\
\text { - Share story made from LHC. } \\
\text { - Begin constructing narrative for your DF. }\end{array}$ & $\begin{array}{l}\text { - Try out your action (developed in the Free Writing Exercise). } \\
\text { - Try the two cyber psychology 'fat' and 'thin' fantasy exercises: } \\
\text { http://anybody.squarespace.com/cyber_psychologist/2006/3/23/e } \\
\text { xercise-1-fat-fantasy.html } \\
\text { - Comment on this reflection in your journal and on the process of } \\
\text { storying using multimodality. } \\
\text { - In small groups liaise with each other to find YouTube clip(s) } \\
\text { relating to body image. } \\
\text { - Don't forget: The Journal Assignment is due in the next } \\
\text { session! }\end{array}$ \\
\hline 5 & $\begin{array}{l}\text { Creating the Digital Fiction I } \\
\text { - Sharing YouTube clips. } \\
\text { - Discussion: media representation vs. reality. } \\
\text { - Review challenges, brainstorm coping } \\
\text { - solutions. } \\
\text { - Exercise: Learning Pathways Grid } \\
\text { - Exercise: Building potential narratives }\end{array}$ & $\begin{array}{l}\text { - Using the Storyboarding sheets given to you (also on } \\
\text { Blackboard), storyboard your digital fiction. } \\
\text { - More time? Go back to the cyberpsychologist try out the } \\
\text { exercises you haven't done or redo ones you enjoyed: } \\
\text { http://www.any-body.org/ } \\
\text { - Alternatively, look up other Dove Real Beauty Sketches, or go } \\
\text { back to Body Gossip's channel. }\end{array}$ \\
\hline 6 & $\begin{array}{l}\text { Creating the Digital Fiction II } \\
\text { - Exercise: Learning Pathways Grid } \\
\text { - Exercise: Developing digital fiction }\end{array}$ & Finish the first draft of your digital fiction. \\
\hline 7 & $\begin{array}{l}\text { Digital Fiction Workshop } \\
\text { - Exercise: Workshop your digital fiction } \\
\text { drafts. } \\
\text { - Revise your DFs. }\end{array}$ & Revise and finish your digital fiction. \\
\hline 8 & $\begin{array}{l}\text { Showcase \& Wrap-up } \\
\text { - Finishing touches \& workshop on DFs. } \\
\text { - Share DFs. } \\
\text { - Wrap-up paperwork. }\end{array}$ & $\begin{array}{l}\text { Remember to hand in your Digital Fiction assignment by } \\
\text { tomorrow. }\end{array}$ \\
\hline
\end{tabular}


Tables:

\begin{tabular}{|c|c|}
\hline Undesirable & Desirable \\
\hline Text-heaviness & Interactivity \\
\hline $\begin{array}{c}\text { Inappropriate level of instruction } \\
\text { (either too much or too little) }\end{array}$ & Contextualized instructions \\
\hline Unrelated topics & Backstory \\
\hline Negativity & Timer/indicator of location in narrative \\
\hline Lack of resolution \& closure & Relatable issues \& characters \\
\hline 'Weirdness' & $\begin{array}{c}\text { Demonstrable distinction between the } \\
\text { mundane \& the exotic }\end{array}$ \\
\hline & $\begin{array}{c}\text { Choices in journey/pathways with different } \\
\text { outcomes, both positive and negative }\end{array}$ \\
\hline
\end{tabular}

Table 1. Undesirable and desirable aspects of DFs, according to participants 


\section{Figures:}

\section{Types of Media used}

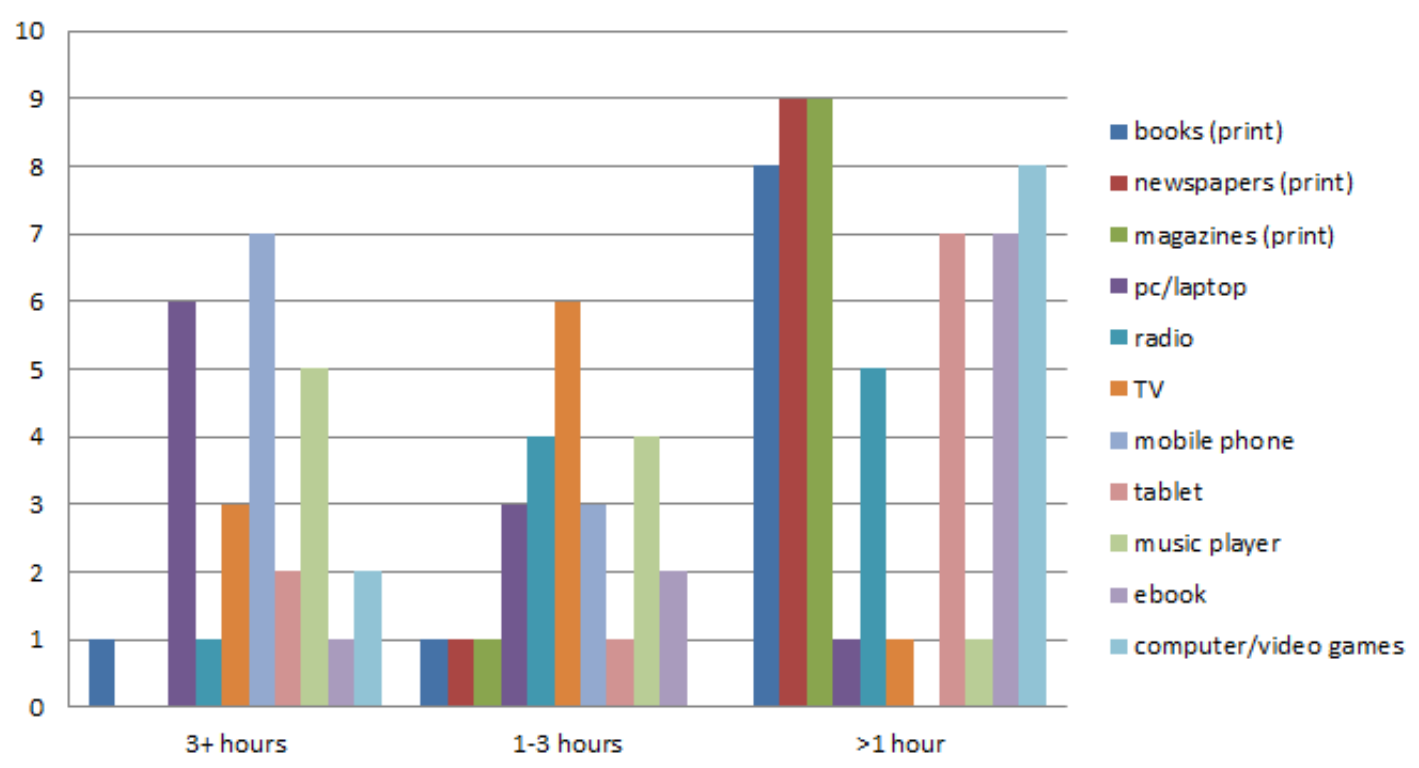




\section{Figure captions:}

Figure 1: Participant reading practices 